\title{
8
}
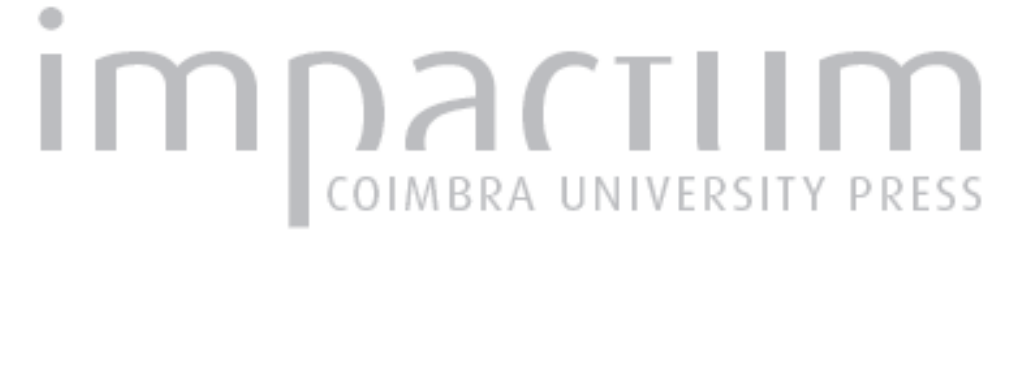

\section{Oficinas de didática do latim: uma proposta de materiais e recursos}

Autor(es): $\quad$ Balula, Ana; Cravo, Cláudia; Pereira, Susana

Publicado por: Imprensa da Universidade de Coimbra

URL persistente:

URl:http://hdl.handle.net/10316.2/41484

DOI:

DOI:https://doi.org/10.14195/0872-2110_60_11

Accessed : $\quad$ 26-Apr-2023 10:55:09

A navegação consulta e descarregamento dos títulos inseridos nas Bibliotecas Digitais UC Digitalis, UC Pombalina e UC Impactum, pressupõem a aceitação plena e sem reservas dos Termos e Condições de Uso destas Bibliotecas Digitais, disponíveis em https://digitalis.uc.pt/pt-pt/termos.

Conforme exposto nos referidos Termos e Condições de Uso, o descarregamento de títulos de acesso restrito requer uma licença válida de autorização devendo o utilizador aceder ao(s) documento(s) a partir de um endereço de IP da instituição detentora da supramencionada licença.

Ao utilizador é apenas permitido o descarregamento para uso pessoal, pelo que o emprego do(s) título(s) descarregado(s) para outro fim, designadamente comercial, carece de autorização do respetivo autor ou editor da obra.

Na medida em que todas as obras da UC Digitalis se encontram protegidas pelo Código do Direito de Autor e Direitos Conexos e demais legislação aplicável, toda a cópia, parcial ou total, deste documento, nos casos em que é legalmente admitida, deverá conter ou fazer-se acompanhar por este aviso.

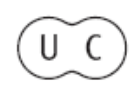


COIMBRA • 2015

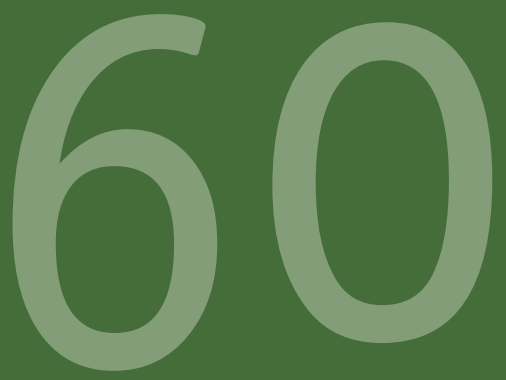

\title{
BOLETIM DE
}

\section{ESTUDOS CLÁSSICOS}

\author{
ASSOCIAÇÃO \\ PORTUGUESA \\ DE ESTUDOS \\ CLÁSSICOS \\ INSTITUTO \\ DE ESTUDOS \\ CLÁSSICOS
}




\title{
OFICINAS DE DIDÁTICA DO LATIM: UMA PROPOSTA DE MATERIAIS E RECURSOS
}

\section{WORKSHOP IN DIDACTICS OF LATIN: PUTTING FORWARD MATERIALS AND RESOURCES}

\author{
ANA BALULA \\ CENTRO DE INVESTIGAÇÃO “DIDÁTICA E TECNOLOGIA NA FORMAÇÃO \\ DE FORMADORES" \\ ESTGA - UNIVERSIDADE DE AVEIRO \\ balula@ua.pt
}

CLÁUDIA CRAVO

CECH - UNIVERSIDADE DE COIMBRA

claudiacravo@hotmail.com

\author{
SUSANA MARQUES \\ CECH - UNIVERSIDADE DE COIMBRA \\ smp@fl.uc.pt
}

Resumo: Como é do conhecimento geral, o ensino das Línguas Clássicas tem vindo a perder expressão no contexto português. A recente oficialização da disciplina de "Introdução à Cultura e às Línguas Clássicas” para o Ensino Básico, como oferta de escola, veio ajudar a revitalizar o interesse nesta área. Consequentemente, têm sido promovidas algumas iniciativas de formação para apoiar os professores envolvidos. 
Este foi, assim, um dos principais objetivos subjacentes à criação das Oficinas de Didática do Latim, que se realizaram em e-learning e agregaram professores de todo o país. Neste trabalho, apresenta-se em detalhe um dos produtos destas Oficinas, mais concretamente um conjunto de materiais e recursos especialmente dirigido a Clubes e Projetos de Escola. Além disso, a título de exemplo, também se avança com possibilidades de didatização, tendo em conta as Metas Curriculares definidas para algumas disciplinas de 5.. ano, numa perspetiva de interdisciplinaridade.

Palavras-chave: ensino do Latim; didática do Latim; formação de professores; formação contínua; Cultura e Línguas Clássicas.

Abstract: As widely known, the teaching of Classical Languages has been losing expression in the Portuguese context. The recent formalization of the discipline "Introduction to Classical Culture and Languages" for primary education, as school offer, came to help revitalize the interest in this area. Consequently, a series of training initiatives have been developed to support the teachers involved. This was thus one of the main objectives underlying the creation of an e-learning Workshop in Didactics of Latin, which involved teachers from all around the country. In this paper, one of the products of these workshops is depicted, specifically a set of materials and resources to be used in Clubs and School Projects. In addition, didactization possibilities are also put forth, taking into account the Curricular Targets set for some $5^{\text {th }}$-grade courses, from an interdisciplinary viewpoint.

Keywords: Latin teaching; didactics of Latin; teacher training; continuous training; Classic Culture and Languages.

\section{CONTEXTO}

Numa sociedade dominada pela cultura da imagem e pelo mundo cibernético, que se impõe de modo irrevogável, os professores de Estudos 
Clássicos são, mais do que nunca, impelidos a inovar e a renovar os seus métodos de ensino. Tal premência tornou-se mais evidente quando, no final do ano letivo de 2014/2015, se conseguiu que o Ministério da Educação e Ciência (MEC) oficializasse a disciplina de "Introdução à Cultura e às Línguas Clássicas" para o Ensino Básico, como oferta de escola. Esta proposta foi implementada em vários estabelecimentos de ensino já em 2015/2016, o que ilustra a imediata recetividade aos temas clássicos.

Muitas pessoas têm vindo a trabalhar com afinco na tentativa de apoiar a lecionação desta disciplina, o que se tem traduzido na realização de Círculos de Estudos proporcionados por Centros de Formação, bem como na criação de uma página do $\mathrm{MEC}^{1}$, na qual se apresenta o enquadramento geral da disciplina, informação sobre projetos na área e se disponibiliza um Forum de apoio aos professores. Na Faculdade de Letras da Universidade de Coimbra (FLUC), aqueles que lidam mais de perto com a formação inicial de professores têm vindo também a procurar contribuir de forma empenhada para apoiar todos quantos se dedicam ao ensino dos Estudos Clássicos no Ensino Básico e Secundário. Um grupo de docentes do Centro de Estudos Clássicos e Humanísticos (CECH) e do Centro de Investigação "Didática e Tecnologia na Formação de Formadores" (CIDTFF) uniu esforços e implementou as Oficinas de Didática do Latim ${ }^{2}$ (ODL). O objetivo principal das ODL, que decorreram durante todo o mês de outubro de 2015, consistiu em levar os participantes a reciclar e a reinventar, de forma colaborativa e partilhada, os seus conhecimentos na área da Cultura e das Línguas Clássicas, fazendo uso, sempre que assim entendessem, das Tecnologias de Informação e Comunicação (TIC). Com esse intento, foi concedida ênfase particular

\footnotetext{
${ }^{1}$ Vide http://www.dge.mec.pt/introducao-cultura-e-linguas-classicas.

${ }^{2}$ As Oficinas de Didática do Latim foram promovidas pelo Centro de Estudos Clássicos e Humanísticos da Universidade de Coimbra e pela Associação Portuguesa de Estudos Clássicos e contaram com o apoio do Núcleo de Estudos em Ensino da Faculdade de Letras da Universidade de Coimbra e do Projeto Especial de Ensino a Distância da Universidade de Coimbra.
} 
ao uso efetivo de ferramentas (TIC) para a produção e didatização de materiais, no contexto específico do ensino do Latim. Pretendeu-se, assim, suprir a falta de oferta de formação específica, a nível nacional, nesse domínio.

As ODL foram muito participadas e geraram discussões interessantes e pertinentes, bem como propostas concretas de planos de aula originais e inovadores na área da Didática do Latim e da Cultura Clássica. Apresenta-se aqui um exemplo dos trabalhos realizados, procurando servir, em especial, professores que se encontram neste momento a lecionar a disciplina de "Introdução à Cultura e às Línguas Clássicas", e sobretudo quem está a desenvolver trabalhos no âmbito de Clubes ou Projetos de Escola. Serão ainda descritos alguns pressupostos tidos em conta aquando da criação dos materiais, nomeadamente no que diz respeito à sua adequação ao nível de ensino (2.ำ ciclo do Ensino Básico) e à forma como a temática e a abordagem didática se poderiam articular com outras disciplinas do currículo, neste caso, do 5.ำ ano, como se passa a descrever.

\section{PROPOSTA DE MATERIAL DIDÁTICO}

Em termos gerais e tal como se apresenta abaixo, os materiais propostos incluem cinco questões $(\mathrm{Q})$, que incidem sobre três áreas temáticas: a saudação (Q1), as partes do corpo (Q2 e Q3) e o vestuário e adereços romanos (Q4 e Q5). Tratando-se de temas diferentes, procurou-se conferir alguma unidade à ficha de trabalho, criando um enredo lógico e realista, formulado imediatamente antes de cada uma das atividades, para que os alunos sentissem alguma empatia com o que lhes era pedido. Por outras palavras, foi imaginada uma figura com a qual os alunos se podiam facilmente identificar através do próprio enredo da história - ou seja, o André, que tinha visto um pequeno vídeo no Youtube (Q1), que se transportou para a época retratada no vídeo e que desenhou a 
sua visão de um soldado (Q2), etc. Quanto às ilustrações, estas foram criadas por um aluno de 5. ano e por um investigador do CECH, José Luís Brandão, o que permitiu resolver questões de direitos de autor, reforçar a fiabilidade histórica e garantir alguma coesão interna à parte gráfica. Paralelamente, e com base na própria ficha de trabalho, foram ainda desenvolvidos alguns exercícios online com recurso a três ferramentas de criação de conteúdos, a serem usados em contexto de aula ou fora de aula, de acordo com o que o professor considerar mais adequado.

Em termos de opções didático-pedagógicas subjacentes aos diversos exercícios criados, no que diz respeito à Q1, esta foi pensada com dois objetivos: por um lado, para dar início ao enredo contextual, transversal a toda a ficha; por outro lado, para apresentar formas de saudação em língua latina. Estas recuperam terminologia muito próxima da que se usa na língua portuguesa - bene ('bem'), male ('mal'), etc. -, o que, em combinação com a componente visual usada (imagens dos soldados), permite uma fácil identificação/compreensão, por parte dos alunos, do vocabulário apresentado. Todavia, é introduzido algum grau de dificuldade (relativa) com o vocábulo meliuscule, através do qual o professor pode chamar a atenção dos alunos para a construção de diminutivos, e com o termo mediocriter que, por analogia com o Português, pode induzir os alunos a uma tradução imprecisa, pelo que carece de explicação por parte do professor.

Do ponto de vista da estratégia didática, e ainda que tradicionalmente o Latim não seja entendido como língua de comunicação per se (Carlon 2013), considera-se que as expressões e o vocabulário em causa podem ser utilizados oralmente em contexto de aula, para que os alunos comecem a familiarizar-se com a pronúncia do Latim.

Em relação à Q2 e à Q3 da ficha de trabalho em análise, na primeira (Q2), a estratégia utilizada foi a descrita para a Q1 (seguindo exatamente os mesmos pressupostos didáticos). Já no que diz respeito à Q3, optou-se por tratar vocabulário latino referente a diversas partes do corpo e por solicitar aos alunos que encontrassem o termo correspondente 
em Português. Ainda que seja apresentada de forma inversa (do Latim para o Português), esta opção didática, tal como a anterior, também permite que os alunos desenvolvam o seu raciocínio lógico e analítico no processo de associação de étimos. Trata-se de uma estratégia que promove o reforço positivo que é dado ao aluno, uma vez que se baseia no conhecimento que este detém da sua própria língua materna.

Foram ainda incluídos exemplos de expressões fixas, relacionadas com as áreas vocabulares em causa, que podem ser interessantes para entender algumas expressões (idiomáticas ou não) ainda hoje usadas em Português no nosso dia-a-dia. Esta é uma opção que pode igualmente ser vantajosa para o alargamento vocabular dos alunos em ambas as línguas.

Ainda em relação ao tema do corpo humano, foi criada uma apresentação com a ferramenta Popplet ${ }^{3}$, intitulada Corpus Humanum ${ }^{4}$. Este recurso didático online pode ser usado com finalidades diversas, dependendo das características da turma em causa, assim como dos objetivos do professor. A título de exemplo, poderá ser utilizado para identificar/ discutir a proximidade semântica de palavras portuguesas derivadas dos étimos latinos apresentados ou para incentivar a tradução dos vocábulos latinos com base na sua similitude com as formas portuguesas correspondentes. Deste modo, poderá funcionar como síntese para estudo autónomo do aluno, ou ser projetado pelo professor antes de se realizarem os exercícios em causa (Q2 e Q3), para explorar o vocabulário oralmente, para corrigir a resposta dos alunos à Q2, ou para consolidar (numa aula posterior) o que foi abordado na ficha de trabalho.

No que concerne à $\mathrm{Q} 4$ e à $\mathrm{Q} 5$, estas incidiram sobre a área temática do vestuário e adereços romanos. Na Q4 é pedido aos alunos que organizem as letras dadas para descobrirem a palavra latina que corresponde à imagem; na Q5 é-lhes solicitado que façam um autorretrato

\footnotetext{
${ }^{3}$ Esta ferramenta está disponível em http://popplet.com/app/\#/public. Para mais detalhes vide http://ed-uc.uc.pt/moodle/mod/page/view.php?id=14885, área denominada Instrumenta et Fontes nas ODL.

${ }^{4}$ Esta apresentação online está disponível em http://popplet.com/app/\#/2758073.
} 
usando peças de vestuário e adereços romanos. o primeiro exercício pode considerar-se de maior complexidade, embora este aspeto dependa dos conhecimentos dos alunos e das estratégias complementares aplicadas pelo professor. A título de exemplo, para alunos com pouco (ou nenhum) contacto prévio com o Latim, fica a sugestão de trocar a ordem da Q5 com a Q4 ou de combinar os dois exercícios, incitando os alunos a descobrir os vocábulos pedidos na Q4 com base na listagem apresentada na Q5.

Para a área temática do vestuário e adereços romanos foram também criados dois exercícios de palavras-cruzadas online, desta feita utilizando a ferramenta HotPotatoes ${ }^{5}$, intitulados Vestimenta Viri e Vestimenta Mulieris ${ }^{6}$. Realça-se que os exercícios foram pensados em Latim (incluindo as instruções), solicitando-se que se insira a palavra portuguesa correspondente à palavra latina apresentada. Estes exercícios podem servir para consolidar os conhecimentos dos alunos (numa perspetiva de trabalho autónomo em casa ou em sala de aula) ou para corrigir as respostas à Q5, uma vez que o que se altera é o suporte, mas o vocabulário em estudo é o mesmo.

Por último, criou-se ainda um exercício de resposta múltipla e de resposta curta em Socrative ${ }^{7}$, intitulado Corpus Humanum et Vestimenta ${ }^{8}$. Trata-se de um exercício que pode ser projetado e realizado em aula (oralmente ou usando um computador pessoal, tablet ou smartphone) ou ser disponibilizado pelo professor em ambiente online, para os alunos

\footnotetext{
${ }^{5}$ Esta ferramenta está disponível em http://hotpot.uvic.ca/. Para mais detalhes vide http://ed-uc.uc.pt/moodle/mod/page/view.php?id=14885, área denominada Instrumenta et Fontes nas ODL.

${ }^{6}$ Exercícios disponíveis em http://ed-uc.uc.pt/moodle/mod/page/view.php?id=14887 (Plano de aula 10> Materiais).

${ }^{7}$ Esta ferramenta está disponível em http://www.socrative.com/. Para mais detalhes vide http://ed-uc.uc.pt/moodle/mod/page/view.php?id=14885, área denominada Instrumenta et Fontes nas ODL.

${ }^{8}$ Estes exercícios estão públicos e podem ser importados depois de instalada a ferramenta localmente, usando o código: SOC-18540068.
} 
acederem fora de aula. Tal como o nome indica, pode ser usado como exercício de síntese das temáticas abordadas em aula.

Por fim, resta acrescentar que a estratégia do professor pode sempre ir mais além da mera apresentação de vocabulário, na medida em que estamos perante conteúdos temáticos que podem facilmente articular-se com disciplinas curriculares de 5.ano, como se passa a exemplificar na secção que se segue.

\section{ARTICULAÇÃO DIDÁTICA INTERDISCIPLINAR}

Como relevam alguns autores (e.g. Fendt 2000, Pappas 2005), as línguas têm uma vertente transversal na sua natureza e o seu ensino e aprendizagem é mais eficaz quando acontece em contexto e numa perspetiva interdisciplinar. Assim, do ponto de vista da possibilidade de articulação dos materiais propostos com outras disciplinas que constam do currículo de 5. ano, foram analisados os Programas e as Metas Curriculares disponíveis no site do $\mathrm{MEC}^{9}$ e concluiu-se que essa articulação se pode concretizar, por exemplo, com as disciplinas de Português ${ }^{10}$ e de História e Geografia de Portugal ${ }^{11}$.

No que concerne à disciplina de Português, o papel do Latim é totalmente incontornável, desde logo se se atender à história da língua. Ainda assim, e como mero exercício teórico, analisou-se o documento "Programa e Metas Curriculares de Português do Ensino Básico" (em particular para o 5. ano) no intuito de tentar identificar para que domínios de referência, objetivos e descritores de desempenho se poderiam rentabilizar os materiais e recursos acima apresentados.

\footnotetext{
${ }^{9}$ Vide http://www.dge.mec.pt/programas-e-metas-curriculares-0.

${ }^{10}$ Vide http://www.dge.mec.pt/sites/default/files/Basico/Metas/Portugues/pmcpeb_julho_2015.pdf, p.68.

${ }^{11}$ Vide http://www.dge.mec.pt/sites/default/files/ficheiros/eb_hgp_metas_curriculares_2_ciclo.pdf, p.6.
} 
Conclui-se que o domínio de referência mais óbvio é o da 'Gramática', mais especificamente traduzido em dois objetivos:

- no objetivo "23. Explicitar aspetos fundamentais da morfologia" e nos descritores de desempenho "1. Deduzir o significado de palavras complexas a partir dos elementos constitutivos (radical e afixos)" e "2. Detetar processos de derivação de palavras por afixação (prefixação e sufixação)”. Tal como em Português, também as palavras latinas podem ter vários elementos constitutivos. Partindo do vocabulário trabalhado na Q3 e em articulação com o professor de Português, podem explicar-se termos como por exemplo: supercilium: super 'acima de'+cilium 'pálpebra' > 'acima da pálpebra'; de supercilia (plural de supercilium) derivou o termo português 'sobrancelha' ('sobre' + 'celha'). Em relação aos processos de derivação de palavras, poder-se-ia partir, por exemplo, de vocábulos como digitus, nasus, oculus para explicar, respetivamente, termos como 'digitalizar, nasalidade, oculista', todos eles derivados por sufixação; ou da palavra caput para explicar vocábulos portugueses como 'decapitar, decapitação', derivados por prefixação.

- no objetivo "26. Reconhecer propriedades das palavras e formas de organização do léxico." e mais concretamente nos descritores de desempenho "1. Identificar e estabelecer relações de significado entre palavras: sinonímia e antonímia." e "2. Identificar e organizar famílias de palavras." Ainda usando o vocabulário abordado na Q3 e a título de exemplo, a partir do vocábulo manus poder-se-ia elaborar uma família de palavras do género 'manual, manípulo, manusear, manufatura, etc.'; a partir de dens, 'dental, dentífrico, dentista, etc'; a partir de digitus, 'digital, dígito, digitalização, etc'; a partir de os, oris 'ósculo (de osculum, diminutivo de os, a significar 'boca pequenina'), oral, oralidade, etc.'. 
No que diz respeito à disciplina de História e Geografia de Portugal, e mais uma vez tendo em conta o exposto no documento "Programa e Metas Curriculares de História e Geografia de Portugal do Ensino Básico" (5.ano), o domínio de referência que sobressai é "A Península Ibérica: dos primeiros povos à formação de Portugal (século XII)", em particular no que concerne ao subdomínio "Os Romanos na Península Ibérica", nomeadamente em dois objetivos:

- no objetivo "Conhecer e compreender o processo de conquista romana da Península Ibérica”, sobretudo no descritor de desempenho “5. Caracterizar (economicamente, socialmente e politicamente) os lusitanos por oposição aos romanos." Tendo por base o vocabulário tratado e as imagens apresentadas na Q4 e na Q5 e, eventualmente, em coordenação com o professor de História e Geografia de Portugal, poderia sublinhar-se a ideia de que, embora a língua seja a herança principal da presença romana na Península Ibérica, a influência deixada pela romanização em terras lusitanas aconteceu nos mais diversos domínios, até no próprio modo de vestir. Seria interessante, a esse respeito, citar Plutarco, Sertório 14.3-4, onde, a propósito da importância da educação do povo lusitano, se refere, entre vários outros aspetos, que os Lusitanos sentiam um grande prazer ao verem os filhos irem à escola vestidos com togas bordadas ao estilo romano, que Sertório fazia questão de $\operatorname{pagar}^{12}$. Em relação ao vestuário, será também curioso chamar a atenção dos alunos para nomes portugueses de indumentária, decalcados do Latim, usados ainda atualmente na tradição litúrgica, que é por natureza conservadora: 'estola, dalmática, túnica, etc'.

- no objetivo "Conhecer e compreender as mudanças operadas na Península Ibérica durante a romanização", em especial no descritor

${ }^{12}$ Vide comentário à tradução deste passo in Morais 2015: 368. 
de desempenho "4. Conhecer a origem latina da Língua Portuguesa", que, por sua vez, também remete para a análise feita no âmbito da disciplina de Português.

É importante realçar que nesta secção não se esgotaram todas as hipóteses de interdisciplinaridade com disciplinas do $5 .^{\circ}$ ano e muitas outras poderiam ser equacionadas no âmbito do $2 . .0$ e do $3 .^{\circ}$ Ciclos - pode ser disso exemplo a possibilidade de articulação com a disciplina de Ciências Naturais, nomeadamente no que se refere ao sistema esquelético (cf. e.g. umerus, cubitus), ou com as disciplinas de Educação Visual e de Educação Tecnológica, no que diz respeito a texturas, padrões, técnicas de desenho no geral, etc.

\section{CONSIDERAÇÕES FINAIS}

Em jeito de balanço, pode-se afirmar que a modalidade em $e$ -learning e o enfoque das ODL num público-alvo específico permitiram, efetivamente, uma interação constante e profícua entre os participantes. Esta opção potenciou o envolvimento de um conjunto de pessoas heterogeneamente distribuído em termos geográficos, desde Braga até ao Porto, passando por Coimbra, Figueira da Foz, Lisboa, e indo até ao Algarve e mesmo aos Açores. É ainda significativo salientar-se que, para além dos materiais aqui apresentados, foram discutidas mais 11 propostas de plano de aula e respetivos materiais. Tendo em conta a duração das ODL (1 mês) e o facto de a maioria dos participantes não estar em dedicação exclusiva, estes dados parecem indiciar, claramente, o interesse dos envolvidos na formação dada.

Fica a nota de que todos os Planos de Aula resultantes das ODL podem ser consultados online, no site do Centro de Estudos Clássicos e Humanísticos da Universidade de Coimbra (CECH), onde existe uma 
página dedicada à Didática, que apresenta o recém-criado projeto Artes Docendi (http://www.uc.pt/iii/research_centers/CECH/projetos/ didaticaLatim), que pretende englobar a investigação e os produtos das iniciativas de formação desenvolvidas na área da Didática dos Estudos Clássicos.

A relevância do conhecimento do Latim para uma apropriação mais sustentada da herança cultural e histórica europeia parece incontestável. Acredita-se que a sua aprendizagem pode verdadeiramente levar os alunos a desenvolver pensamento crítico em questões políticas, económicas, religiosas, sociais, etc., promovendo o respeito pela pluralidade e pela diferença, competências cada vez mais pertinentes no contexto social em que vivemos. Deste modo, e no que diz respeito à interdisciplinaridade subjacente ao Latim, é interessante verificar que esta transparece no modo como estão formuladas as Metas Curriculares de várias disciplinas, sendo no entanto cada vez mais urgente apoiar os professores no sentido de equacionarem soluções eficazes para a sua operacionalização.

\section{BILIOGRAFIA}

Brandão, J. L. e Oliveira, F. (coords.) (2015), História de Roma Antiga I: das origens à morte de César. Coimbra.

Carlon, J. M. (2013), “The Implications of SLA Research for Latin Pedagogy: Modernizing Latin Instruction and Securing its Place in Curricula", Teaching Classical Languages 4 (2): 106-122. ISSN 2160-2220. Disponível em http:// tcl.camws.org/sites/default/files/Carlon_0.pdf [consultado a 01-12-2015].

Connolly, P. (1978), O exército romano. Carlos, A. trad., Lisboa.

Fendt, Kurt (2000), "Contextualizing Content: The Potential of Hypermedia for Interdisciplinary Language and Culture Learning", in Kecht, M.-R. and von Hammerstein, K. (eds.), Languages Across the Curriculum: Interdisciplinary Structures and Internationalized Education. Columbus, OH: National East Asian Languages Resource Center, The Ohio State University: 201-223. 
MEC - Programa e Metas Curriculares do Ensino Básico - 2º ciclo. Disponível em http://www.dge.mec.pt/programas-e-metas-curriculares-0 [consultado a 01-12-2015].

Melo, A. (1995), “O ensino do vocabulário latino: etimologia e evolução semântica”, In As Línguas Clássicas II: investigação e ensino. Coimbra.

Miquel, P. (1988, 2ª ed.), No tempo das legiões romanas. Silva Castro, J. C. trad., Lisboa.

Morais, R. (2015), "De Sula ao "1. triunvirato": o legado de Crasso e Pompeio Magno” in Brandão, J. L. e Oliveira, F. (coords.) (2015), História de Roma Antiga I: das origens à morte de César. Coimbra: 363-388.

Office of the Secretary-General Pedagogical Development Unit. Disponível em http:// www.eursc.eu/getfile/1962/2 [consultado a 05-12-2015].

Pappas, A. (2005). "Veni, Vidi, Vici: Third Principal Parts or Caesar's Triumphal Message? An Interdisciplinary Approach to Teaching Beginning Latin", CPL Online 2(1): 1-15. Disponível em https://www.kcl.ac.uk/sspp/departments/education/study/pgce/documentation/Latin-with-Classics-Handbook.pdf [consultado a 010-12-2015]. 


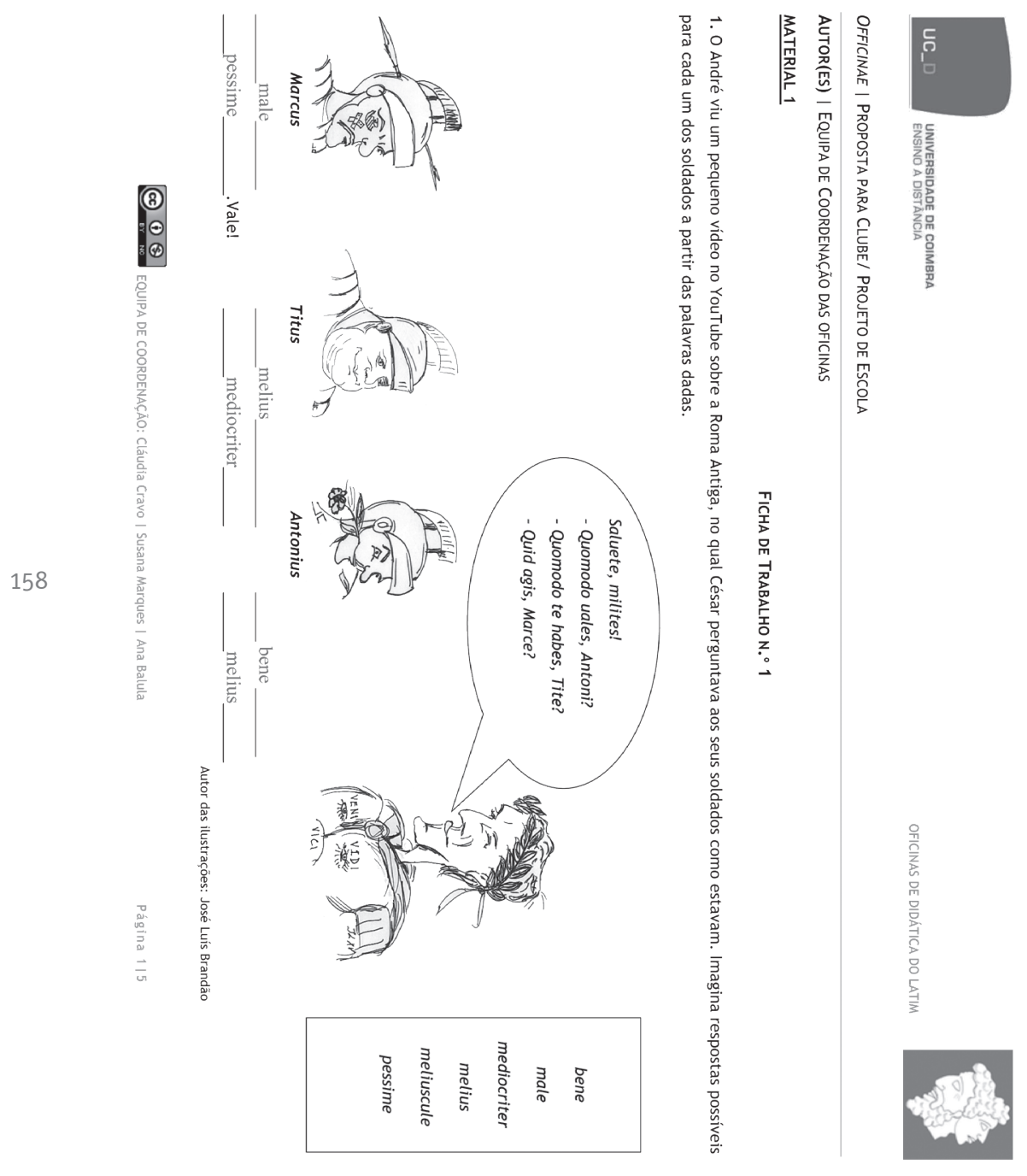


1.1. Et tu? Quomodo uales?

(pessime, male, mediocriter, meliuscule, melius, bene)

2. Depois, imaginando-se naquela época, divertiu-se a desenhar um soldado um pouco desorientado, com o capacete (galea, ae) ao contrário. Identifica as partes do rosto do soldado em Latim, usando as palavras dadas abaixo.

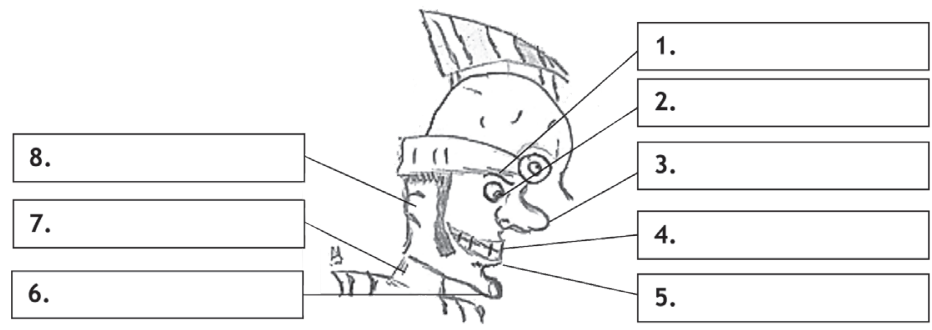

os, oris | nasus, $i \mid$ oculus, $i \mid$ mentum, $i$ | auris, is | collum, $i$ | dens, tis | supercilium, ii

Soluções: 1. supercilium, ii; 2. oculus, i; 3. nasus, i; 4. dens, tis; 5. os, oris; 6. mentum, i; 7. collum, i; 8. auris, is

Vocabulário extra:

- frontem contrahere (franzir o sobrolho);

- in oculis aliquem ferre (ter um fraquinho por alguém). 
3. O André lembrou-se, entretanto, da figura de Marcus depois de perder uma batalha - até a roupa the tinham roubado! Ficou apenas de capacete (galea, ae), cuecas (subligaculum, i) e sandálias (caligae, arum). Identifica as partes do corpo do soldado que correspondem às palavras latinas.
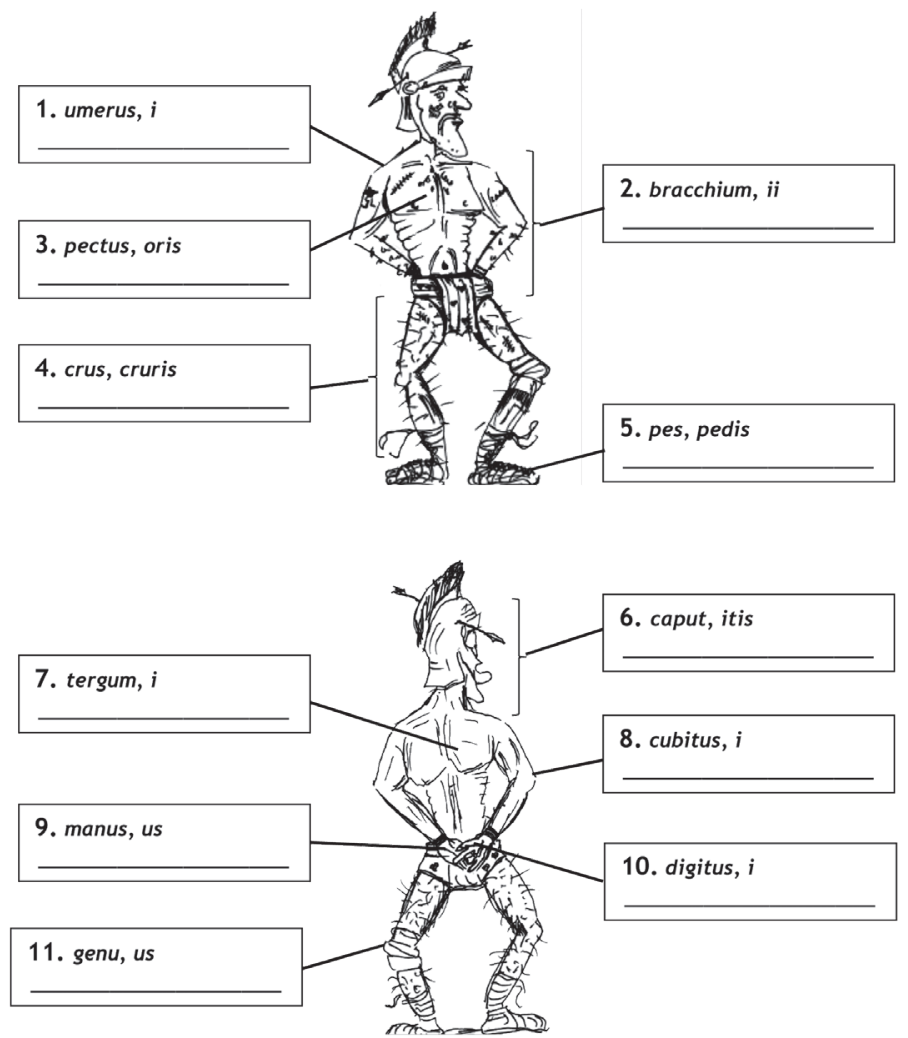

Autor das ilustraç̄es: José Luís Brandão

Soluções: 1. ombro; 2. braço; 3. peito; 4. perna; 5. pé; 6. cabeça; 7. costas; 8. cotovelo; 9. mão; 10. dedo; 11. joelho

Vocabulário extra:

- $\quad$ in manus meas uenire (chegar-me às mãos);

- e manibus effugere (escapar das mãos);

- nec caput nec pedes habere (não ter pés nem cabeça). 


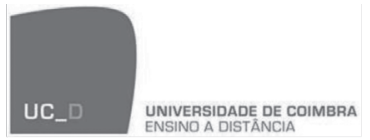

OFICINAS DE DIDÁTICA DO LATIM

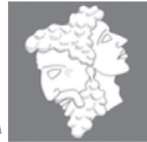

4. O André notou ainda que, no século I a.C., as pessoas não se vestiam como agora. Identifica as diversas peças de vestuário e adornos romanos, organizando as letras dadas.

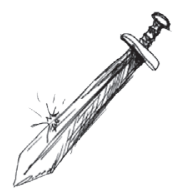

uisdgla

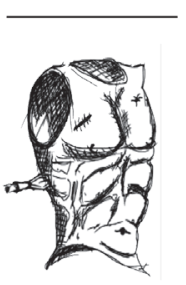

colira

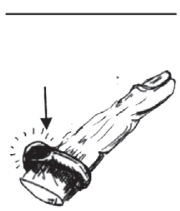

lusnua

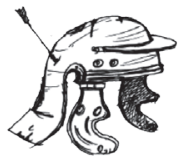

aelga

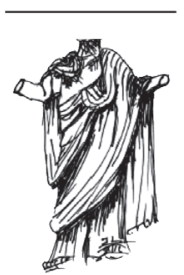

gato

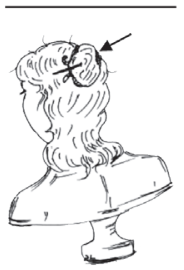

falibu
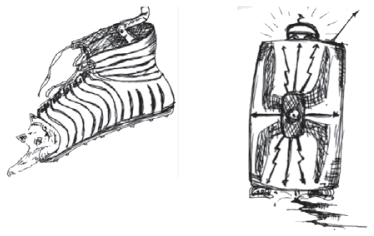

stumcu
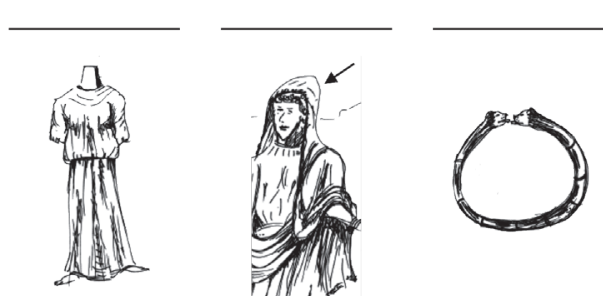

taslo

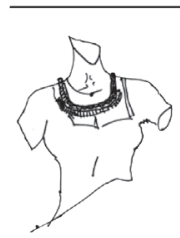

lemoni

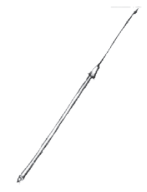

milup

III)

lapal

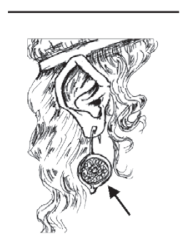

enauris

Soluções: gladius, ii (espada pequena); galea, ae (capacete); caliga, ae (sandália); scutum, i (escudo quadrado grande); pilum, $i$ (lança pontiaguda); lorica, ae (couraça); toga, ae (toga); stola, ae (vestido comprido); palla, ae (mantilha); armilla, ae (pulseira); anulus, $i$ (anel); fibula, ae (gancho); monile, is (colar); inaures, ium (brincos); tunica, ae (túnica) 


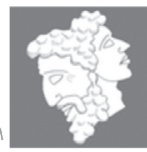

5. Imagina-te tu também na Roma do século I a.C. Faz um autorretrato de corpo inteiro e identifica as peças de vestuário e adereços que usarias. Podes, para tal, usar o vocabulário que se apresenta no quadro abaixo.

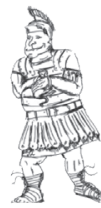

gladius, ii

galea, ae

caliga, ae

scutum, $i$

pilum, $i$

lorica, ae

toga, ae

tunica, ae

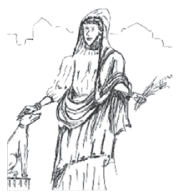

stola, ae

palla, ae

armilla, ae

anulus, $i$

fibula, ae

monile, is

inaures, ium

tunica, ae

Rapaz: gladius, ii (espada pequena); galea, ae (capacete); caliga, ae (sandália); scutum, i (escudo quadrado grande); pilum, $i$ (lança pontiaguda); lorica, ae (couraça); toga, ae (toga); tunica, ae (túnica)

Rapariga: stola, ae (vestido comprido); palla, ae (mantilha); armilla, ae (pulseira); anulus, $i$ (anel); fibula, ae (gancho); monile, is (colar); inaures, ium (brincos); tunica, ae (túnica)

Vocabulário extra: lorica segmentata (armadura segmentada, por tiras 


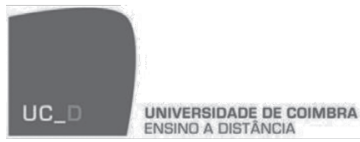

monile, is

inaures, ium

tunica, ae

Rapaz: gladius, ii (espada pequena); galea, ae (capacete); caliga, ae (sandália); scutum, $i$ (escudo quadrado grande); pilum, $i$ (lança pontiaguda); lorica, ae (couraça); toga, ae (toga); tunica, ae (túnica)

Rapariga: stola, ae (vestido comprido); palla, ae (mantilha); armilla, ae (pulseira); anulus, i (anel); fibula, ae (gancho); monile, is (colar); inaures, ium (brincos); tunica, ae (túnica)

Vocabulário extra: lorica segmentata (armadura segmentada, por tiras) 